\title{
Diverticular Fistula of the Female Urethra on Lithiasis at the District Health Center (CSREF) in Communeii, Bamako, Mali
}

\author{
Tounkara Idrissa1, Diarra Abdoulaye ${ }^{2}$, Traoré Amadou', Coulibaly B. Bakary ${ }^{1}$, \\ Kanté Abdoulaye ${ }^{4}$, Dembélé Dabéré Ives ${ }^{1}$, Thiam Souleymane ${ }^{5}$, Ouattara Kassoum ${ }^{1}$, \\ Kanté Lassana ${ }^{3}$, Konate Madiassa ${ }^{3}$, Koné Assitan ${ }^{3}$, Ongoiba Oumar ${ }^{6}$, Sangaré Modibo4, \\ Dembélé Bakary Tiètiki ${ }^{3}$, Diakité Ibrahim³ ${ }^{3}$, Sidibé Yoro ${ }^{3}$, Bah Amadou ${ }^{3}$, Coulibaly Yakaria ${ }^{3}$, \\ Togo Adégné ${ }^{3}$, Diallo Gangaly ${ }^{3}$
}

${ }^{1}$ Chirurgie générale du Centre de santé de référence de la commune II de Bamako, Mali

${ }^{2}$ Chirurgie générale du Centre Hospitalier Universitaire de Kati, Mali

${ }^{3}$ Chirurgie générale Centre Hospitalier Universitaire Gabriel TOURE de Bamako, Mali

${ }^{4}$ Chirurgie générale du Centre Hospitalier Universitaire du POINT G de Bamako, Mali

${ }^{5}$ Hôpital régional de Gao, Mali

${ }^{6}$ Hôpital régional de Tombouctou, Mali

Email: ^idrisstounk@yahoo.fr

How to cite this paper: Idrissa, T., Abdoulaye, D., Amadou, T., Bakary, C.B., Abdoulaye, K., Ives, D.D., Souleymane, T., Kassoum, O., Lassana, K., Madiassa, K., Assitan, K., Oumar, O., Modibo, S., Tiètiki, D.B., Ibrahim, D., Yoro, S., Amadou, B., Yakaria, C., Adégné, T. and Gangaly, D. (2019) Diverticular Fistula of the Female Urethra on Lithiasis at the District Health Center (CSREF) in Communeii, Bamako, Mali. Surgical Science, 10, 83-88.

https://doi.org/10.4236/ss.2019.103011

Received: February 21, 2019

Accepted: March 15, 2019

Published: March 18, 2019

Copyright $\odot 2019$ by author(s) and Scientific Research Publishing Inc. This work is licensed under the Creative Commons Attribution International License (CC BY 4.0).

http://creativecommons.org/licenses/by/4.0/

\begin{abstract}
The diverticulum of the female urethra or sub-urethral pouch is in the form of a cul-de-sac lined with mucous membrane through the muscular layer of the urethra. Thus, it is a site of stasis, urinary infection, formation of calculus or even malignant tumor. The diverticula of the urethra or sub-urethral pouches in women have a prevalence of $0.5 \%$ to $6 \%$ depending on the series. We report the case of a 61-year-old patient operated for a diverticulum on fistulized urethra complicated lithiasis. Our patient had five pregnancies and five births when she consulted for dysuria, urinary burns evolving since a year. The urogenital examination revealed a partially stenotic urethral meatus and a $3-\mathrm{cm}$ large fistulized intravaginal peri-urethral mass allowing urine leak. The mass was painful and hard at palpation. We performed transvaginal diverticulectomy. The follow-up was simple and the probe was removed two weeks after the surgery. An atomo-pathological examination of the resected diverticulum concluded an aspect compatible with lithiasis urethritis.
\end{abstract}

\section{Keywords}

Diverticulum, Urethral, Fistula, Lithiasis, Bamako 


\section{Introduction}

The female urethra or urethral pouch is in the form of a dead end, which is bordered by mucous membranes through the muscular layer of the urethra. It is thus a site of stasis, urinary tract infection, calculus or even malignant tumors [1] [2] [3]. Urethral calculations are rare and more often encountered in the case of either shrinkage or sub spacing of the urethra [4]. The urethral pouches in women have a prevalence of $0.5 \%$ to $6 \%$ depending on the series [5]. They are rarely complicated by lithiasis. The symptomatology is polymorphic and non-specific resulting in the late stage discovery of the complications such as urethra-vagina fistula type diverticular [6], calculations [1] [4] [7] [8] or intra-diverticular tumor [1] [2] [3]. We report the case of a 61-year-old woman operated for complicated diverticular fistula of urethra with lithiasis.

We wanted to highlight the rarity of the case. A diverticulum of the urethra created by a calculus enclosed in the female urethra. Then the diverticulum becomes infected and fistulises, letting the urine flow.

\section{Observation}

A 61-year woman with a history of five pregnancies and five births consulted for dysuria, urinary burning urgency evolving for a year. Anamnesis highlighted a history of chronic cough, cesarean section, urinary bilharzia in untreated childhood and a sensation of a vaginal mass. Inspection and palpation revealed a partial stenosis of the urethral meatus and a 3-cm large fistulized peri-urethral intra-vaginal mass with urine leak (Figure 1). The mass was painful and hard at palpation.

The radiography without preparation of the lower urinary tract showed the presence of a radio-opaque calculus in the middle third of the urethra (Figure 2) with a normal ultrasound of the bladder. The calculus was locked in the ureter and not in the bladder. Ultrasound is also dependent operator.

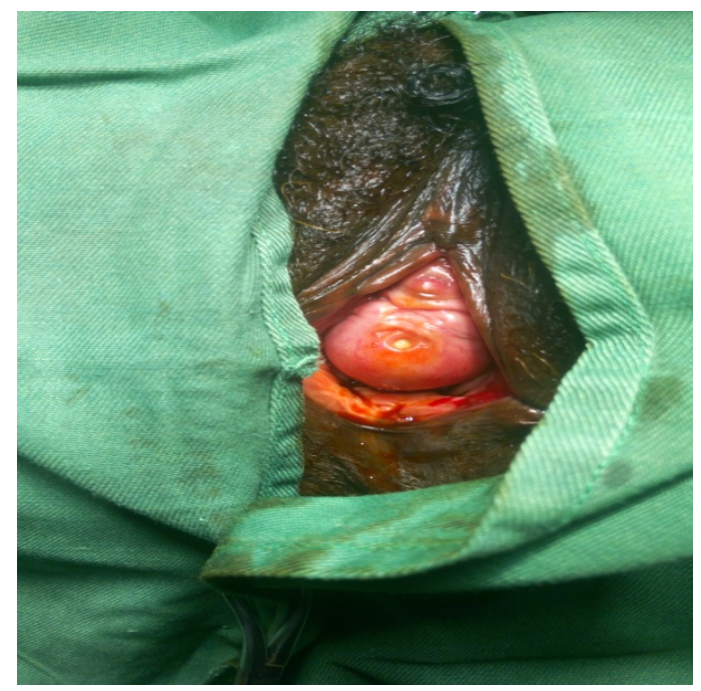

Figure 1. Intra-vaginal mass with urine leak. 


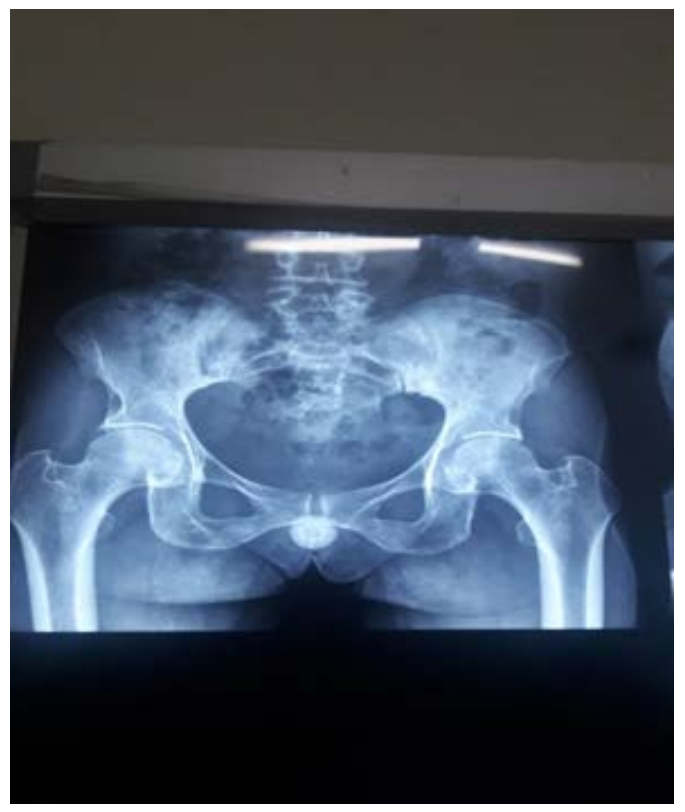

Figure 2. Radio-opaque calculus in the middle third of the urethra.

The cyto-bacteriological examination of the urine did not identify any germs and the urine culture was sterile after unspecified medical treatment. The patient underwent transvaginal diverticulectomy, which consisted of an incision of the inverted $U$ vaginal mucosa, transverse incision and dissection of the peri-urethral fascia, exposure and opening of the gallery ablation of the calculus (Figure 3), excision of the walls, collar and ablation of the niche. We performed overedge closure in three layers with absorbable wire. The urethra was closed longitudinally on probe Ch18, the fascia peri-urethral transverse and the vaginal mucosa at $3 / 0$. The post-surgery evolution was simple and the probe was removed two weeks after the surgery. The anatomopathologic examination of the resected diverticulum showed an aspect compatible with a urethritis gallstone in the urethra.

\section{Discussion}

The incidence of urethral diverticulum in women varies from $0.6 \%$ to $6 \%$ [4] [5]. Congenital urethral diverticula have already been reported in newborns and little girls [1] [2] [5] but urethral diverticula are mostly of acquired origin and occur between the third and fifth decades or at an older age [2] [4]. The consensual factors in the genesis of acquired urethral diverticula are: infection, the fistulisation of the peri-urethral glands in the urethral light [1] [2] [4]. This is the most admitted theory; obstetrical and urethral trauma iatrogenic [1] [4] [6]; The obstruction of the distal urethra [2]. Female urethral calculi complicate urethral diverticula in up to $10 \%$ of the cases depending on the series [1] [4] [5] [7]. The stagnation of the infected urine in the diverticulum, the epithelial peeling and the precipitation of the mineral elements contained in the urine are the conditions 


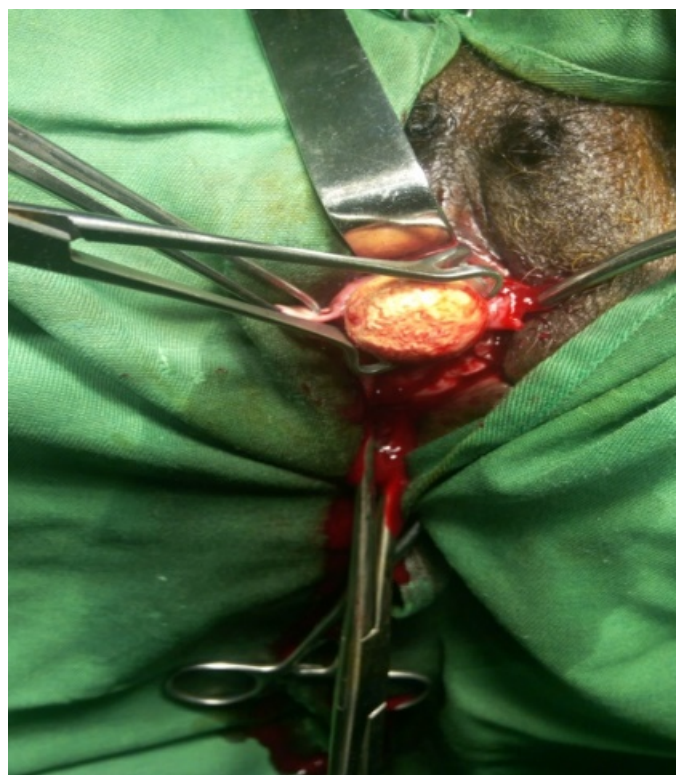

Figure 3. Ablation of the calculus.

that favor the formation of intra-diverticular calculi [2]. The most commonly accepted hypothesis is ROUTH [8], according to which infection and repeated obstructions of the peri-urethral glands result in the formation of urethral cysts. The diagnosis is evoked on the symptomatic triad of the three "D's": Dribbling, Dyspareunia, and Dysuria [9]. The pus enters the urethral meatus during the maneuvers pressing the pouch such as sexual intercourse and the vaginal toilet. The urination in two times by emptying of the pocket is very suggestive of the diagnosis. Repetitive urinary tract infections, Pollakiuria and urinary urgency are present in half of the cases [10]. However, $4 \%-20 \%$ of the urethral diverticula are asymptomatic and are incidental findings during a clinical or radiological examination [11]. The clinical examination allows to establish the diagnosis of urethral pouch in over $60 \%$ of cases [10]. The pouch was in the form of a sensitive anterior vaginal swelling which released few drops of pus or urine under pressure. In our patient, palpation revealed a swollen fistulized hard urethral diverticulum. Retrograde and Voiding Urethra-cystographie (UCRM) is the first-line radiological examination [11], the voiding cliché highlighted the diverticular collar and allowed us to appreciate its characteristics [1]. Recent literature reports new diagnostic modalities, such as nuclear magnetic resonance imaging (MRI) with endorectal antenna [11]. Many authors [1] [2] are unanimous that total vaginal diverticulectomy is the treatment of choice of complicated urethral calculation. This explains our choice of this technique. The diverticulectomy allowed not only easy removal of the calculus but also the resection of tissue from the diverticular wall for the anatomo-pathologic examination. Cases of intradiverticular tumors have already been reported in the literature [1] [3]. We performed a transvaginal diverticulectomy associated with an open of the urethral meatus to extract the calculus. Such surgery exposes the patient to complications namely fistulas, urethral stenosis, and urinary incontinence of effort in 3.3\% - 
$10 \%$ of the cases [8]. Recurrences of urethral diverticula are exceptional after removal. However, active urethral infection, local inflammatory reactions and bladder drainage difficulties may favor its recurrence [12]. The best prevention of these complications remains the control of vaginal surgery and the caution when dissecting the diverticular collar to ensure a complete resection of the subdivision [11].

\section{Conclusion}

The female urethral fistula on lithiasis is rare and easy to diagnose. It is suspected in the presence of signs of the lower urinary tract associated with a hard and painful peri-urethral anterior intravaginal mass allowing urine leak. The standard X-ray of the pelvis can be of a critical contribution to the diagnosis. The total diverticulectomy is the reference treatment.

\section{Conflicts of Interest}

There is no conflict of interest in this article.

\section{References}

[1] Ganabathi, K., Dmochowski, R. and Sirls, L.T. (1995) Female Urethra Diverticular. Progrès en Urologie, 5, 335-351.

[2] Gera, P.K., Matthews, K. and Smith, G. (2007) Urethral Diverticulum in a Female Child. Journal of Pediatric Urology, 3, 148-150. https://doi.org/10.1016/j.jpurol.2006.04.006

[3] Thibault, F., Mouton, A., Sibony, M., Cussenot, O., Sebe, P., Gattegno, B., et al. (2008) Cancer de l'urètre féminin, à propos de trois cas et revue de la littérature. Progrès en Urologie, 18, 318-322. https://doi.org/10.1016/j.purol.2008.01.001

[4] Beatrice, J. and Strebel, R.T. (2008) Giant Calculi in Urethral Diverticula. CMAJ, 178, 994. https://doi.org/10.1503/cmaj.071198

[5] Hosseinzadeh, K., Furlan, A. and Torabi, M. (2008) Pre- and Postoperative Evaluation of Urethral Diverticulum. AJR, 190, 165-172. https://doi.org/10.2214/AJR.07.2094

[6] Nielsen, V.M., Nielsen, K.K. and Vedel, P. (1987) Spontaneous Rupture of a Diverticulum of the Female Urethra Presenting with a Fistula to the Vagina. Acta Obstetricia et Gynecologica Scandinavica, 66, 87-88. https://doi.org/10.3109/00016348709092964

[7] Martinez-Maestre, A., Gonzalez-Cejudo, C., Canada-Pulido, E. and Garcias-Marcias, J.M. (2000) Giant Calculus in a Female Urethral Diverticulum. International Urogynecology Journal, 11, 45-47. https://doi.org/10.1007/s001920050009

[8] Marshall, S. (1981) Urethral Diverticula in Young Girls. Urology, 17, 243-245. https://doi.org/10.1016/0090-4295(81)90039-X

[9] Mauroy, B. (1996) Urèthre normal et pathologique de la femme. Encyclopédie Médico-Chirurgicale (Elsevier, Paris), Néphrologie-Urologie, 18-400-A-10, 27 p.

[10] Ganabathi, K., Dmochowski, R., Sirls, L.T., Zimmern, P.E. and Leach, G.E. (1995) Diverticules de l'urèthre féminin. Progrès en Urologie, 5, 335-351.

[11] Anidjar, M., Martin, O., Meria, P., Hermieu, J.F., Delmas, V. and Boccon Gibod, L. (1993) Poche sous-uréthrale de la femme: A propos de 6 cas. Progrès en Urologie, 3, 
778-786.

[12] Mouad, S., Jihad, E.G., Tarik, K., Khalid, E.K., Abdellatif, K. and Ahmed, I.A. (2014) Le diverticule de l'urètre féminin: A propos de 18 cas. Pan African Medical Journal, 18, 78 . 